\title{
AFETIVIDADE E APRENDIZAGEM ESCOLAR: REFLEXÕES ACERCA DO PROCESSO ENSINO- APRENDIZAGEM
}

\author{
Zildene Francisca PEREIRA \\ Universidade Federal de Campina Grande/UFCG \\ denafran@yahoo.com.br
}

Resumo: Discutimos, neste artigo, a relação existente entre o processo de ensino-aprendizagem e a afetividade, a partir da teoria walloniana como nosso principal referente teórico. Para tanto temos como objetivos: discutir a importância da afetividade na prática pedagógica e conhecer os estágios de desenvolvimento, considerando o processo histórico do qual a criança faz parte. Compreender a afetividade para além do entendimento na maneira de agir maleável e suave faz com que possamos ampliar nosso conhecimento acerca desse conceito tão difundido, atualmente, nas práticas pedagógicas, mas nem sempre compreendido em toda sua amplitude. Desse modo, estudar essa temática é um desafio constante, pois são inúmeras as dificuldades impostas em sala de aula cotidianamente.

Palavras-chave: Afetividade. Desenvolvimento infantil. Prática docente. Psicogenética walloniana.

Abstract: We discuss in this article, the relation between the process of teaching and learning and affection, from the Wallonian theory as our main theoretical reference. For this we aim to: discuss the importance of affectivity in pedagogical practice and to know the stages of development, considering the historical process in which the child belongs. Understanding the affection beyond understanding in the way to act soft and smooth enables us to expand our knowledge of this concept so widespread nowadays in teaching practices, but not always understood in its full extent. Thus, study this theme is a constant challenge because several difficulties imposed in the classroom every day. 
Keywords: Affectivity. Child development. Teaching practice. Wallonian Psychogenetics.

\section{Introdução}

Sou eu, eu mesmo, tal qual resultei de tudo, Espécie de acessório ou sobressalente próprio, Arredores irregulares da minha emoção sincera, Sou eu aqui em mim, sou eu.

Quanto fui, quanto não fui, tudo isso sou. Quanto quis, quanto não quis, tudo isso me forma. Álvaro de Campos (2007, p. 396)

Iniciamos este artigo com uma justificativa que, a nosso ver, nos abriu um leque de entendimentos ou até mesmo de novos questionamentos acerca da discussão relacionada à afetividade. Escolhemos a teoria walloniana como principal referente teórico por percebermos que sua teoria nos fundamenta na compreensão do desenvolvimento infantil a partir do conhecimento da criança concreta em suas diferentes fases de desenvolvimento, bem como a compreensão de sua interligação com o meio no qual está inserida. Como diz a epígrafe, formamo-nos e nos constituímos pessoa na inter-relação com o outro, a partir de nossas experiências pessoais.

Outra razão que, a nosso ver, foi de fundamental importância foi a compreensão, ao longo das leituras, de que a criança se individualiza no social, no coletivo, levando-nos a um maior entendimento sobre as reais necessidades de um trabalho conjunto e individualizado nas atividades realizadas em sala de aula. Wallon nos possibilita um novo olhar para a prática docente, priorizando a dimensão afetiva sem perder de vista a cognitiva e a motora, considerando que são essas instâncias que constituem a pessoa.

Reconhecermos a necessidade de uma maior compreensão acerca da afetividade, pautada, neste momento, na teoria psicogenética walloniana que é de fundamental importância, mas antes de adentrarmos mais especificamente na discussão teórica 
torna-se imprescindível para um maior entendimento destacarmos o que o senso comum compreende o que seja a afetividade em sala de aula. Vimos que essa tem relação direta com o entendimento na maneira de agir de forma suave, maleável, gostar de beijar, de abraçar, de estar perto e cuidar do outro, de fazer com que todos ao nosso redor sintam-se acolhido cotidianamente, sejam eles relacionados à vida pessoal, profissional e/ou durante o processo ensino-aprendizagem, mais especificamente.

\section{Afetividade e desenvolvimento infantil}

Para continuarmos o entendimento deste conceito, voltamo-nos, inicialmente, para o que explicita Wallon (1973/1975) acerca das fases de desenvolvimento da criança a partir de cinco estágios: impulsivo emocional que vai de 0 a 1 ano; sensório-motor e projetivo - de 1 a 3 anos; do personalismo - de 3 a 6 anos; estágio categorial - de 6 a 11 anos; e puberdade - adolescência que vai dos 11 anos em diante. Em cada estágio, torna-se imprescindível considerarmos não apenas a idade indicativa para cada fase, mas principalmente que tipo de atividade e interesse estão presentes (MAHONEY, 2000). Hoje é imprescindível uma revisão, considerando não ser a idade que determinará se uma criança está em um determinado estágio ou em outro, mas as condições propícias, ou não, em que essa criança está imersa.

A teoria walloniana nos leva à compreensão de que cada estágio de desenvolvimento será vivido pela criança de acordo com funcionamentos orgânicos, bem como sob a influência de fatores sociais, pois como nos diz Wallon $(1973 / 1975$, p. 162) o ser humano "[...] é um ser íntimo e essencialmente social", considerando que a consciência do eu só se dá na relação com o outro. Com essa afirmação, Wallon nos aponta que cada estágio é vivido de acordo com a integração organismo-meio social. Esses fatores orgânicos e sociais se interpenetram para constituir a pessoa.

Cada fase corresponderá a um tipo de comportamento assumido pela criança e será uma preparação para o estágio seguinte, sendo também interligado ao estágio anterior. Tal postura

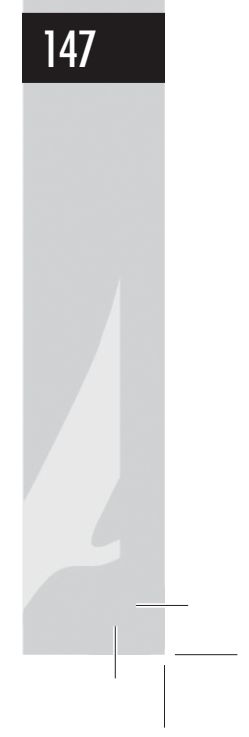




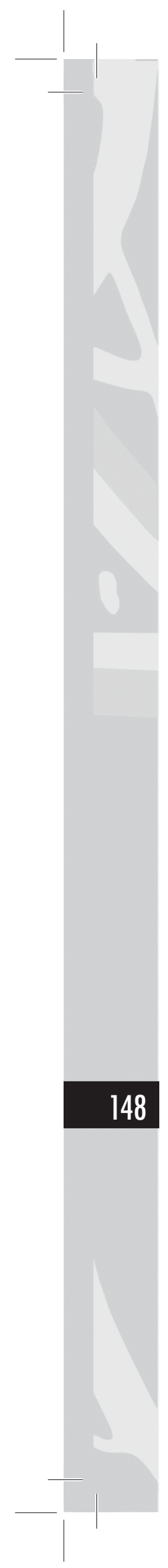

justifica-se, por exemplo, no fato de que os estágios e idades correspondentes a cada fase foram identificados por Wallon, considerando crianças de seu tempo e de sua cultura. Desse modo, poderemos pensar como se dá a relação da criança hoje a partir da quantidade de informações recebidas diariamente, considerando o contexto, a época em que nasceram, seus costumes, crenças, bem como a vivência na era digital.

Desse modo, faz-se necessário obtermos uma melhor compreensão do que mobiliza professoras alfabetizadoras a encontrar sentido no ensinar, considerando a afetividade na prática docente e suas implicações para o processo ensino-aprendizagem. Enfatizaremos as contribuições de Wallon (1973/1975; 1941/1995), autor que embasa a escrita desse artigo e destacaremos um conjunto de pesquisadores que dialogam com a temática afetividade: Dantas (1992); Galvão (1995); Leite (2006); Mahoney e Almeida (2000; 2003 ; 2004; 2007) dentre outros, com os quais dialogamos para embasar as reflexões aqui propostas.

Entendermos que a forma como Wallon escreve é na verdade um dos grandes conflitos e desafios, principalmente pelos termos médicos utilizados em seus escritos, bem como pela forma densa e complexa de expor suas reflexões, dúvidas e achados ao longo de seus estudos. Para entendê-lo, é necessário um ir e vir de aproximações, distanciamentos, cansaço, ânimo, acertos e erros durante toda a compreensão de sua teoria. Contudo, ao desatarmos o nó que conduz ao entendimento, a leitura deixa de ser cansativa e passa a ser um meio para encontrar subsídios a inúmeros questionamentos e inquietações no campo educacional, mais especificamente em relação ao trabalho em sala de aula.

Wallon (1973/1975) estudou o psiquismo em sua origem e transformações, considerando os domínios afetivo, cognitivo e motor. Estudou a criança por ela mesma, sem ter como parâmetro as experiências dos adultos, pois o sujeito se constrói na interação com os outros, e cada interação é vivida ao seu modo, com suas especificidades.

A Teoria de Desenvolvimento proposta por Wallon nasceu de observações e comparações como nos confirma Tran Thong 
(2007) no Prefácio da Coleção Textos Fundantes de Educação quando apresenta a obra $A$ criança turbulenta, tese de doutorado de Henri Wallon, apresentada no curso de Letras em 1925,

[...] Wallon, após um exame crítico dos diferentes métodos em uso, elabora seu próprio método de análise genética comparativa multidimensional. Este método consiste em empregar uma série de comparações combinadas de maneiras diversas segundo as necessidades: comparações entre os comportamentos da criança patológica, da criança normal, do adulto patológico, do adulto normal atual e das civilizações primitivas do animal; comparações entre as crianças normais da mesma idade $e$ idades sucessivas; comparações entre as crianças patológicas de diferentes níveis e categorias; etc. (1925/2007, p. 10).

Wallon destacou a possibilidade de estudarmos um indivíduo concreto em toda sua amplitude. Para o autor, a utilização da palavra indivíduo refere-se exatamente ao individual, um ser completo com todos os conjuntos funcionais, situando seu contexto, sua cultura, o meio familiar em que está inserido, bem como as dimensões mais amplas de convivência entre a criança e outras pessoas do meio ao qual está inserida.

Para entendermos a teoria walloniana, é necessário fugir, inicialmente, da noção de fragmentos compreendida por alguns profissionais da área de educação, especialmente os que consideram apenas o aspecto motor, ou o afetivo ou o cognitivo. Torna-se imprescindível considerar que todos esses aspectos estão interligados - um afeta e é afetado pelo outro.

Ao considerarmos a interligação entre esses aspectos podemos enfatizar que compreendemos a afetividade como um conjunto funcional que responde pelos estados de bem-estar e mal-estar, vividos pelo indivíduo. É um conceito amplo que ultrapassa a noção do contato físico, epidérmico, em alguns casos, acompanhado de elogios efêmeros. É a disposição que o

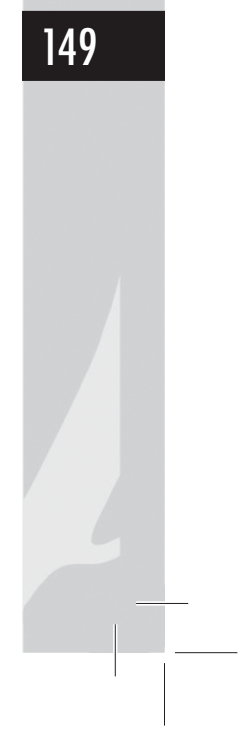




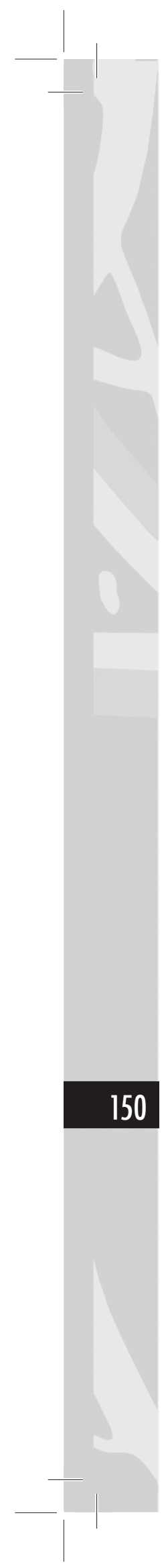

ser humano tem para ser afetado pelo mundo interno e externo e para também afetar o outro. Esse entendimento nos foi possível a partir de inúmeras leituras e discussões da teoria walloniana e de estudiosos da temática.

Assim, a afetividade se faz presente em todas as etapas do desenvolvimento infantil, e o indivíduo estabelece diversas maneiras de lidar com cada nova exigência. Para uma criança pequena, o colo, o afago são aspectos significativos e fazem bem para uma determinada ocasião; para uma criança maior, as palavras de carinho, incentivo, conforto e encorajamento já trazem marcas diferenciadas; para um adolescente ou jovem, o respeito, a escuta atenta, o entendimento, o diálogo favorecerão uma relação saudável e de constante aprendizado, pois “[...] As manifestações epidérmicas da 'afetividade da lambida' se fazem substituir por outras, de natureza cognitiva tais como respeito e reciprocidade [...]" (DANTAS, 1993, p. 75).

Podemos afirmar que as discussões referentes à afetividade vêm crescendo consideravelmente considerando as práticas pedagógicas, nas relações em sala de aula, entre professores e alunos, em busca de uma reflexão mais aprofundada da visão fragmentada de homem. A questão da afetividade foi deixada de lado por muitos anos, voltando a ser considerada e discutida a partir do final da década de 1970 (LEITE, 2006). O que se tinha anteriormente era uma visão dicotômica da razão versus emoção, corpo versus alma, cognitivo versus afetivo - herança da separação cartesiana. Torna-se imprescindível entender que "[...] o pensamento dominante sempre caracterizou a razão como a dimensão mais importante, sendo a emoção [...] considerada o elemento desagregador da racionalidade, responsável pelas reações inadequadas do ser humano" (LEITE, 2006, p. 16-17).

$\mathrm{Na}$ escola somos formados para pensar, comportar e agir mediante normas, regras e limites impostos ao que devemos sentir e em que momento poderemos manifestar, como emoções verdadeiras, o que realmente sentimos. $\mathrm{O}$ aluno, por sua vez, será moldado para aprender os conteúdos sistematizados e ao mesmo tempo como se a consideração de outros aspectos que não fosse apenas o cognitivo retirasse do/a 
professor/a sua autoridade, bem como desconcertasse o curso habitual da rotina de sala de aula.

Nessa compreensão, a aprendizagem escolar era vista apenas pela transmissão de conhecimentos por parte do professor, e o aluno estaria nesse espaço para aprender conteúdos a partir de algumas regras básicas: permanecer sentado, ouvir com atenção, concentrar-se durante todo o horário escolar e realizar as atividades propostas. Exigindo-se, assim, uma postura adequada para esse local, as crianças "[...] aprendem a simular o que estão sentindo e pensando e entram numa espiral negativa" (CASASSUS, 2009, p. 202).

É importante salientar que, além do aspecto afetivo, a dimensão motora do desenvolvimento infantil que, para Wallon, é também um importante campo funcional, foi por muito tempo desconsiderada e poderemos perceber e destacar que "[...] é comum a escola simplesmente esquecer das necessidades psicomotoras da criança e propor atividades em que a contenção do movimento é uma experiência constante" (GALVÃO, 1995, p. 109).

Se adentrarmos em diversas salas de aula, ainda hoje, perceberemos o quanto o controle postural exercido sob crianças, para que essas aprendam o conteúdo proposto, a partir da fixação do olhar, do silêncio e do mínimo de movimentação corporal, ainda se faz presente na relação pedagógica. A partir dessa realidade, podemos indicar que, em parte, esse espaço está fadado ao cansaço, ao desânimo, desestrutura, evasão e/ou expulsão de diversos alunos que vão à escola com a expectativa de encontrar outro ambiente, que favoreça um aprendizado menos doloroso, menos rigoroso em termos de sujeição silenciosa da atenção na aprendizagem dos conteúdos sistematizados.

Afirmamos que a escola está, em parte, fadada ao cansaço porque já existem estudos que demonstram uma realidade voltada à compreensão da relação afetividade e aprendizagem escolar a partir da percepção de que a existência de outra dinâmica pedagógica é possível, especialmente considerando as inúmeras mudanças e cobranças contemporâneas em que passa o ambiente escolar e seus diferentes sujeitos. 
Diante dessa realidade, encontrar sentido para nossas ações em sala de aula, ao questionar as verdadeiras razões que nos impulsionam a agir de uma forma e não de outra, seria um dos primeiros passos em prol do desenvolvimento tanto do aluno, quanto do professor. As formas de comportamento apresentados na escola vêm carregadas de intencionalidades, sejam elas causadoras de bem-estar ou mal-estar para as relações existentes. Nossa trajetória como professores pode nos dar pistas de como compreender o processo ensino-aprendizagem, pois "[...] sabemos que o fio condutor de nossa ação é a experiência de cada um, constituída na trajetória pessoal e profissional [...] decorrente de nossa biografia afetivo-cognitiva (ALMEIDA, 2004, p. 119).

Assim, a reflexão a respeito de nossas experiências mostrará possíveis caminhos a serem trilhados na condução da aula, nas diversas maneiras de relacionamento entre professor e alunos, bem como na construção do conteúdo a ser estudado. Mas nem por isso serão consideradas as melhores saídas ou as únicas, pois, em inúmeros casos, surgirão necessidades de uma maior compreensão teórica acerca dos conhecimentos elaborados ao longo da história de determinados sujeitos - neste caso - crianças em fase inicial de escolaridade e professores alfabetizadores em exercício.

Ao abordar a afetividade, na relação professor-aluno no contexto da alfabetização, hoje primeiro ano, ressaltando os diversos conceitos utilizados pelo senso comum, corremos o risco de idealizar a figura do professor como aquele capaz de ultrapassar toda e qualquer barreira existente na sala de aula, considerando que ele tem que aceitar o aluno com tudo que ele apresenta, independente de causar bem ou mal-estar ao professor, aos colegas e ao processo ensino-aprendizagem. Assim, compreender o processo ensino-aprendizagem a partir do entendimento da afetividade como constituinte do nosso estar no mundo é uma forma de ressignificar saberes, valorizar a busca pelo conhecimento sistematizado, considerar experiências e histórias de vida, percebendo as vivências como permeadas de significações. 
Vimos, no decorrer de inúmeras leituras, que o aluno não é um ser isolado que aprenderá tudo na sala de aula. Essa percepção a partir da literatura especializada veio embasar um olhar já existente e confirmar que cada um tem seu tempo para se desenvolver, para aprender, para encontrar e dar sentido ao que aprendeu, e esse carrega traços de sua individualidade, de experiências que o tornam diferentes, inclusive na construção do conhecimento. Por essas e tantas outras razões é que se faz necessário conhecer a criança concreta em toda sua amplitude de relações e condições de existência no meio em que faz parte (MAHONEY, 2003).

Se voltarmos a discussão para a sala de aula, considerando a compreensão dos diferentes meios, poderemos perceber que o professor nem sempre está preparado ou até mesmo foi formado para essa compreensão mais acurada de marcas individuais que o próprio aluno traz como parte de sua subjetividade.

O professor, por sua vez, conta com uma gama de experiências oriundas de sua convivência com os alunos, que lhe possibilitará conduzir, de forma prazerosa ou não, os conteúdos a serem trabalhados. Mas, o que, muitas vezes, ocorre é a ênfase excessiva no aspecto cognitivo levando-o a sentir incerteza, ansiedade, medo e dilemas por não saber se o trabalho desenvolvido está realmente adequado. Não queremos com essa afirmação responsabilizá-lo pelo desinteresse ou fracasso do aluno, embora ele também tenha sua parcela de responsabilidade, mas que esse possa ser considerado como ser, com saberes e experiências próprias de um determinado convívio social.

Torna-se importante destacar que aceitar o meio social como transitório e com marcas individuais é uma compreensão otimista no sentido de que as possibilidades do indivíduo estão em potencial e que em seu processo de desenvolvimento o meio poderá lhe oferecer limitações, mas, também, possibilidades, é uma constante preparação. Essas construções são, em alguns casos, movidas somente pelo hábito, como automatismos, sem termos necessariamente que pensar sobre. Em muitos casos o que nos falta são oportunidades para chegar a determinadas escolhas, pois o meio, embora influencie de maneira incisiva, 


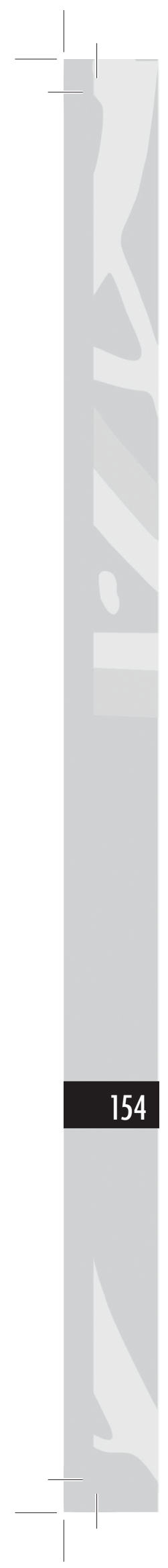

não determina nosso destino. Existe nesse tempo uma escolha que também é pessoal movida por diversas questões.

É imprescindível considerarmos, ainda, em meio a essa reflexão da sala de aula como espaço de construção de saberes que o professor, também, está em processo de aprendizagem, muitas vezes, de forma conflituosa, com preocupação constante se vai dar conta de seu trabalho de forma que o aluno aprenda. Em alguns casos professores se questionam até que ponto os cursos de aperfeiçoamento da prática docente, realizados por diferentes instâncias institucionais, estão condizentes no atendimento aos aspectos afetivo, cognitivo e motor, tão discutidos atualmente. Para Mahoney (2003, p. 11), é imprescindível que “[...] a escola tome consciência do que ela oferece às crianças como modo de existência, como modo de sentir, como modo de se relacionar com a cultura e com as pessoas [...]".

Nesse sentido, podemos entender que as mudanças relativas à compreensão da afetividade como um aspecto menor no desenvolvimento humano, bem como nas relações cotidianas, especialmente em sala de aula, não são mais enfatizadas de modo unilateral, essa concepção está sendo revista, pois, atualmente, alguns educadores consideram que o afetivo e o cognitivo são dimensões indissociáveis "[...] não sendo mais aceitável analisálas isoladamente" (LEITE, 2006, p. 17).

Embora essa compreensão indissociável dos aspectos cognitivos e afetivos, na condução do processo ensinoaprendizagem em sala de aula, seja foco de discussões e estudos, ainda temos muitas visões equivocadas do que seja a afetividade. É possível destacarmos que muitos professores permanecem presos à ideia de o cognitivo se sobrepor para não haver tumulto durante as aulas, nem perda de controle do outro. A concepção de autoridade docente impede, em parte, uma visão ampliada de como poderá ser o processo ensino-aprendizagem que leve à construção do conhecimento a partir de um bom relacionamento professor-aluno como seres que afetam e são afetados de maneira agradável ou não pela própria dinâmica escolar.

Embora existam, ainda, preocupações excessivas com atividades conteudistas como mencionamos anteriormente, 
afloram inquietações que buscam entender o aluno como um ser social e integral. Para entender esse sujeito na perspectiva walloniana, devemos fugir da compreensão fragmentada do indivíduo, pois esse carrega marcas de sua singularidade, seus sentidos e significados mediante experiências vivenciadas, mas também traz impregnados traços do grupo social ao qual pertence, em um dado momento histórico.

Uma das observações destacadas nas pesquisas realizadas sobre a afetividade é a relação estabelecida entre sujeito-objetomediador (LEITE, 2006), levando em consideração que essa relação é também de natureza afetiva e tem como eixo principal a história de cada sujeito mediante o objeto de conhecimento. No caso da criança em fase escolar inicial, o objeto de conhecimento seria a leitura e a escrita. Leite (2006) apresenta pesquisas sobre a afetividade nas quais aparecem histórias de sucesso ligadas a mediadores como parentes e professores que fizeram com que a relação entre sujeito e objeto de conhecimento fosse ressignificada, sendo importante para a constituição individual.

$\mathrm{O}$ processo de aprendizagem, repleto de expectativas por parte dos sujeitos envolvidos, nos possibilita perceber singularidades existentes em cada aluno, através de alguns sinais. Por um lado temos: o silêncio, a realização de todas as atividades, o não questionamento em sala de aula, o bom comportamento e relacionamento com os demais alunos, bem como com o/a professor/a, a suavidade na maneira de falar e agir. Esses aspectos refletem, às vezes, de forma equivocada, uma sensação de bem-estar nesse ambiente alfabetizador. Enfatizamos uma compreensão equivocada, de forma a chamarmos a atenção para as determinações impostas na escola para o que seja um bom comportamento e um bom aluno. $\mathrm{O}$ que nos faz refletir os diferentes entendimentos acerca desses aspectos que aparentemente são causadores de bem-estar.

Por outro lado, temos outros sinais perceptivos que são considerados, em muitos casos, aspectos causadores de mal-estar e de tumulto em sala de aula: o barulho, a agressividade, a não realização das atividades propostas, falar alto, gritar com colegas e professores, a elaboração de muitas perguntas relacionadas ao 


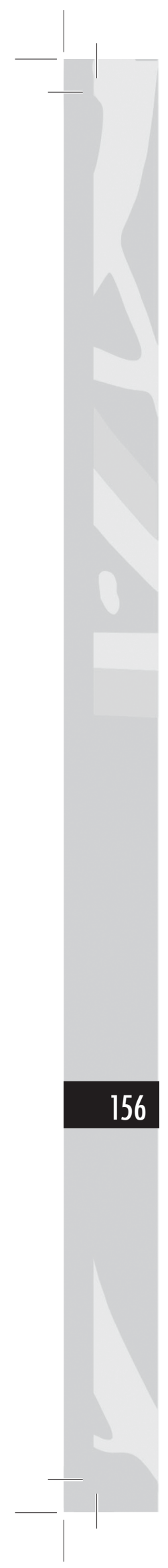

conteúdo e um comportamento inquieto. Da mesma forma que os aspectos citados anteriormente podem trazer uma compreensão equivocada, esses poderão ocasionar o seguinte entendimento: o aluno não quer nada, vem para a escola apenas para bagunçar ou para não ficar em casa e não está preocupado em aprender. Os sinais poderão confundir o professor fazendo-o tomar atitudes nem sempre favoráveis para o processo ensino-aprendizagem e em alguns casos forçando os alunos a se evadirem da escola.

A agressividade é um dos aspectos mais considerados nessa lista, pois a partir do momento em que o aluno foge aos padrões prescritos pela escola ele será punido, sem que o professor tenha clareza das reais condições que o levou a agir de determinada forma. A escola é um espaço com influência mútua e seria imprescindível levar em consideração essas diferentes manifestações, ampliando a necessidade de interlocução entre professor-aluno.

Por um lado, se o professor utiliza normas autoritárias na sala de aula fazendo com que as atividades cotidianas sejam cumpridas sem que o aluno entenda as razões de como serão conduzidas, a relação professor-aluno bem como o processo ensino-aprendizagem poderão seguir caminhos indesejados, dificultando a relação do sujeito com o objeto de conhecimento.

Por outro, se as atividades são colocadas claramente para os alunos e o professor se mostra alguém interessado em seu desenvolvimento de forma autêntica, essa relação poderá ser traçada a partir de novos caminhos que favoreçam o ensino e a aprendizagem. Poderíamos considerar conforme Conte de Almeida que "[...] Não há ato de ensinar-aprender sem a mediação concreta de sujeitos humanos, não havendo, portanto, relação ensino-aprendizagem sem que haja atuação indissociável entre inteligência, afetividade e desejo" (1993, p. 31).

A elaboração de novos conhecimentos, que considere a presença de um transmissor de conteúdos de forma segura e reflexiva - o professor, junto com o aprendiz, aluno - vem permeada de inquietações proporcionadas por dúvidas e questionamentos. $\mathrm{O}$ ensino-aprendizado é considerado um processo indissociável entre sujeitos que constroem 
conhecimento de forma interativa e elaborado significativamente para ambas as partes, pois "Aprender é transformar-se na relação com o outro" (MAHONEY, 2004, p. 19).

Pensar a afetividade e sua relação com a aprendizagem escolar leva-nos à seguinte premissa: as relações estabelecidas em sala de aula são marcadas pela afetividade em seus diversos aspectos: disposição do aluno para permanecer na aula, relações interpessoais expressivas, interação do aluno com o objeto de conhecimento - ler, escrever e contar. A compreensão da afetividade, para além do senso comum, se constitui como um elemento articulador para o processo de alfabetização e é determinante na vida do aluno seja de maneira satisfatória e/ou aversiva.

A teoria psicogenética walloniana nos fundamenta na compreensão do ser integral, a partir dos vários estágios de desenvolvimento pelo qual passa a criança para obtermos uma compreensão mais aprofundada da realidade cotidiana em diversas situações. Mas, essa compreensão não é determinada pela idade em que a criança se encontra, mas pelo estímulo, pelo meio e por sua própria inserção nos diferentes assuntos que envolvem a dinamicidade da inteligência.

É indispensável que o professor tenha esse entendimento para que sejam desenvolvidas habilidades de escuta, olhar atento, agir diferente nas relações estabelecidas no ambiente escolar, diálogo constante, pautados na compreensão de uma educação voltada para o sujeito integral. É fundamental que o professor promova situações agradáveis e de harmonia em sala de aula, mas isso não significa que o professor não tenha autoridade, pois esse é um aspecto que faz parte diretamente de seu papel, especialmente considerando as intervenções que deverão ser realizadas.

A compreensão da afetividade perpassa as relações estabelecidas no âmbito educacional, sendo manifestada pelas reações experienciadas ao longo da história individual de cada um, sejam elas aversivas ou significativas nos diferentes contextos. Mesmo os acontecimentos afetivos sendo de natureza subjetiva terão ligação direta com as relações estabelecidas com o meio, nas interações entre os diversos sujeitos, deixando 


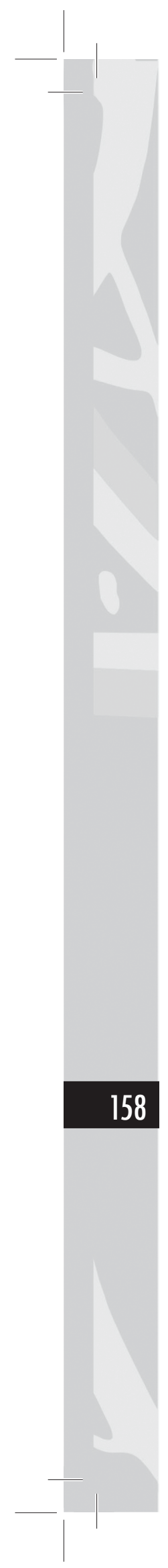

marcas que poderão impulsioná-los ou paralisá-los em determinadas ocasiões.

Pensar a afetividade na relação pedagógica a partir da percepção do senso comum remete-nos, inicialmente, ao entendimento de questões como: o professor ser bonzinho, utilizar tonalidades suaves para falar, não ser rigoroso em sala de aula, escutar e entender as dificuldades dos alunos, beijar e abraçar com certa frequência. Com essa compreensão, em muitos casos, a afetividade é confundida com a permissividade do professor, fazendo com que esse não se perceba como um profissional que tem funções determinadas na escola.

Aos poucos, uma nova compreensão emerge em busca de melhores entendimentos referentes à amplitude desse conceito, ainda que saibamos que boa parte dos professores esquece que os aspectos afetivos se referem também aos estados de medo, ansiedade, tristeza, raiva dentre outros sentimentos que poderíamos citar. A partir das reflexões e análises da teoria podemos perceber que Wallon postula a integração afetividade, cognição e ato motor, e essa é uma relação costumeiramente desarticulada do ensino-aprendizagem escolar, embora as discussões tenham crescido no âmbito educacional.

Grande parte do trabalho de Wallon foi dedicada ao estudo da afetividade, postulando a integração do biológico e do social. Ao fazer a discussão da emoção mostra que essa tem um papel essencial na vida psíquica da criança, pois as relações que ela estabelece com o mundo exterior são de sociabilidade e serão aos poucos expandidas, passando de total sincretismo para a diferenciação, resultado de cuidados elementares do seu meio (DANTAS, 1992).

A afetividade, diferentemente do que conhecemos no senso comum, traz implícita uma concepção que diz respeito "[...] à capacidade, à disposição do ser humano de ser afetado pelo mundo externo e interno por meio de sensações ligadas a tonalidades agradáveis ou desagradáveis" (ALMEIDA e MAHONEY, 2007, p. 17). A discussão da afetividade traz implícito três momentos na sua evolução: a emoção é orgânica, intensa e de curta duração; o sentimento tem um componente 
representacional e é mais duradouro e a paixão é mais intensa, duradoura e com maior autocontrole (WALLON, 1941/1995). Esses três componentes da afetividade indicam que ela não é imutável, pelo contrário, a cada experiência o sujeito terá formas diferenciadas de lidar com as situações apresentadas, através de expressões diversas e de sentido que o próprio sujeito atribuirá nas relações com o meio em que vive.

Para Wallon (1941/1995), são três os mecanismos para agir sobre o meio social e assim podemos destacar: "[...] a contagiosidade, capacidade de contaminar o outro, a plasticidade, capacidade de refletir no corpo os sinais da emoção e a regressividade, que é a capacidade de a emoção fazer regredir a racionalidade e as atividades cognitivas" (DOURADO, 2005, p. 63).

Já o sentimento é diferente da emoção, pois não implica reações imediatas, ele tende a ser controlado, representacional e pode ser expresso pela mímica e pela linguagem, diminuindo, assim, a força que tem a emoção. O adulto consegue observar e refletir antes mesmo de tomar qualquer iniciativa, ele sabe o melhor momento para se expressar, apresentando seus motivos. Na paixão, temos o predomínio do autocontrole, podendo também silenciar a emoção, pois ela não surge antes do estágio personalismo que corresponderá dos 3 aos 6 anos. No caso da criança, ela será capaz de guardar o ciúme e a raiva para amadurecer o que sente (WALLON, 1941/1995, p. 145).

Os vínculos afetivos, por sua vez, iniciam-se nessa relação familiar, momento em que a criança, por meio de movimentos desordenados, consegue mobilizar seu entorno, para responder à satisfação das suas necessidades, esse é o início do processo de aprendizagem. Posteriormente, a criança adquire novas manifestações afetivas na relação com o outro avançando no âmbito cognitivo. "O processo de socialização começa na família e continua no bairro, na escola e em outras instituições e situações sociais" (CASASSUS, 2009, p. 197).

Ao chegar à escola, esses laços serão ampliados, criam-se, dessa maneira, novas relações interpessoais que possibilitarão ou não que o processo ensino-aprendizagem seja prazeroso ou aversivo. Um dos

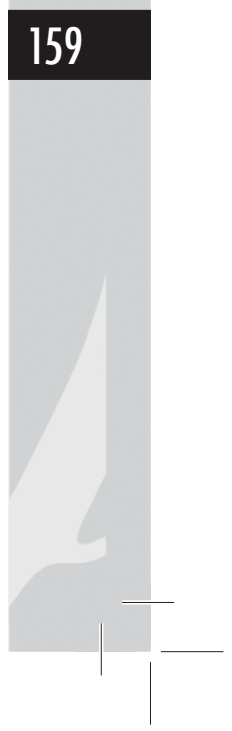




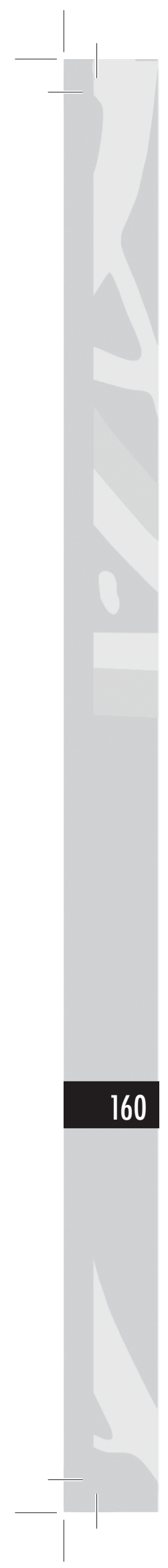

aspectos primordiais na relação professor-aluno é que se tenha clareza das reais necessidades de ambos, que possam compreender o que desencadeia ou desencadeou determinado sentimento e/ou emoção.

É significativo considerar que as etapas de desenvolvimento vivenciadas pela criança não são estagnadas; ao mesmo tempo em que ela está em um determinado estágio, a próxima já estará sendo preludiada, o que na verdade se torna um processo contínuo. Algumas escolhas serão feitas; porém, o que foi supostamente abandonado em um determinado estágio não será destruído. Dessa forma, a criança terá outras possibilidades para vivenciar com outro delineamento as escolhas atuais (GALVÃO, 1995).

\section{Considerações}

Para Wallon (1973/1975), a educação deverá atender às necessidades e interesses dos alunos, e o planejamento é um forte aliado do professor, especialmente considerando a promoção de atividades que provoquem o aprendizado. Sabemos que os desafios impostos em sala de aula, se enfrentados adequadamente, estimulam a ação do aluno e sua vontade de ir além do esperado. Desafios não no sentido de incitar a disputa, mas a cooperação e a suposição de que é possível superar e realizar tal atividade, pois a não superação poderá acarretar uma situação desagradável e um sentimento de fracasso.

Esperamos com essa reflexão, inicial, que os imprevistos ocorridos em sala de aula, pela falta de compreensão da indissociabilidade das dimensões afetivas, cognitivas e motoras, possam ser repensados e refletidos, de modo a rever nossa postura, a forma de enxergar o aluno e de nos perceber como educadores com função determinada na escola.

Sabemos que concluir nãoé uma tarefa fácil, especialmente porque quando pensamos ter chegado a alguma finalização, percebemos que nossas inquietações e dúvidas ficaram mais acentuadas. Por essa razão, temos apenas sínteses provisórias construídas até o momento, mas que poderão ser ampliadas ao longo de muitas outras discussões, reflexões e análises. 
ALMEIDA. L. R. de; MAHONEY, A. A. (Org.). Afetividade e aprendizagem: contribuições de Henri Wallon. São Paulo: Loyola, 2007.

CASASSUS, J. Fundamentos da educação emocional. Brasília: UNESCO; Liber Livro Editora, 2009.

CONTE DE ALMEIDA, S. F. O lugar da afetividade e do desejo na relação ensinar-aprender. Temas em Psicologia, n. 1. São Paulo, 1993.

DANTAS, H. A afetividade e a construção do sujeito na psicogenética de Wallon. In: LA TAYLLE, Y. Piaget, Vigotsky, Wallon: teorias psicogenéticas em discussão. São Paulo: Summus, 1992.

. Emoção e ação pedagógica na infância: contribuição de Wallon. Temas em Psicologia, n. 3, São Paulo, 1993.

DOURADO, I. C. P. Relações Sociais: estudo a partir da teoria de desenvolvimento de Henri Wallon. 2005. Tese (Doutorado em Educação: Psicologia da Educação), PUC-SP, São Paulo, 2005.

GALVÃO, I. Henri Wallon: uma concepção dialética do desenvolvimento infantil. Petrópolis: Vozes, 1995.

LEITE, S. A. da S. Afetividade e práticas pedagógicas. In:

Afetividade e práticas pedagógicas. $1^{\text {a }}$ ed. São Paulo: Casa do Psicólogo, 2006.

MAHONEY, A. A.; ALMEIDA, L. R. de. Contribuições de H. Wallon para a reflexão sobre questões educacionais. In: PLACCO, V. M. N. de S. (Org.). Psicologia e Educação: revendo contribuições. São Paulo: Educ, 2003. 
. (Org.). A constituição da pessoa na proposta de Henri Wallon. São Paulo: Loyola, 2004.

PESSOA, F. Sim, sou eu, eu mesmo, tal qual resultei de tudo. Poesia completa de Álvaro de Campos. Edição Tereza Rita Lopes. São Paulo: Companhia das Letras, p. 396-397, 2007.

TRAN THONG. In: WALLON, H. A criança turbulenta: estudo sobre os retardamentos e as anomalias do desenvolvimento motor e mental. Tradução Gentil Avelino Titton. Petrópolis, Vozes, 2007. (Trabalho original publicado em 1925)

WALLON, H. Psicologia e Educação da Infância. Lisboa: Estampa, 1973/ 1975.

A evolução psicológica da criança. Tradução Cristina Carvalho. Lisboa: Edições 70, 1995. (Trabalho original publicado em 1941) 